\title{
The Species and Population Densities of Root-Knot Nematodes, Meloidogyne spp. (Tylenchida: Heteroderidae) in Grafted and Non-grafted Tomatoes in Greenhouses in Antalya ${ }^{1}$
}

\author{
Kubra Dudu Demir Ergin \\ Usak University, Faculty of Agriculture \\ Plant Protection Department, 64200 Usak, Turkey \\ E-mail: kubradududemir@outlook.com \\ Gulcan Tarla \\ Usak University, Faculty of Agriculture, \\ Plant Protection Department, 64200 Usak, Turkey \\ E-mail: gulcan.tarla@usak.edu.tr \\ ${ }^{1}$ This article is part of the first author's Master's thesis and was completed in Usak University \\ Graduate Education Institute.
}

\begin{abstract}
Root-knot nematodes, Meloidogyne spp. (Tylenchida: Heteroderidae) is a major problem in the world as well as in Turkey. The control of these soil-borne nematodes is very difficult and costly. One of the methods of controlling with this nematode is using grafted seedlings. In regions where greenhouse cultivation, soil and root samples were taken in numbers to represent the greenhouse during the removal of plants after harvest in 2019 - 2020. As a result of the study, infection rates in grafted and non-grafted tomato plants were determined as $16,98 \%(\mathrm{n}=106)$ and $63,56 \%(\mathrm{n}=129)$. In these samples, only Meloidogyne incognita (Kafoid and White) (Tylenchida: Heteroderidae) species was found in the roots of grafted tomato plants in both years. Both M. incognita and Meloidogyne javanica (Treub) (Tylenchida: Heteroderidae) species were detected in the roots of non-grafted tomato plants.

As a result of the counts of the second stage larvae in the study, the mean of population density per 100 gram soil taken from the grafted tomato plants was 132,22 $\pm 55,78$ (between 100 and 300 ) nematodes, while the mean of population density in soil taken from non-grafted tomato plants was 1272,92 \pm 1683,27 (between 100 and 11000 ) nematodes. In addition, when the nematode population densities in soils belong to non-grafted tomato plants in 2019-2020 were examined according to the nematode species, the population density of $M$. incognita was recorded as 1252,13 $\pm 1910,56$ (between 100 and 11000 ) ) nematodes and the population density of $M$. javanica as 1333,33 $\pm 720,64$ (between 300 and 4000) nematodes.
\end{abstract}

Keywords: Antalya, Meloidogyne, population, root-knot, tomato

DOI: $10.7176 / J S T R / 6-13-06$

\section{Introduction}

Tomato, Lycopersicon esculentum Mill (Personatae: Solanaceae) is the second important vegetable product consumed as raw and processed food, after potato, as a cultivated plant grown all over the world today. It is also regarded as a medicinally important plant due to its unique nutritional value, namely, it contains lycopene, beta carotene, flavonoids, vitamin $\mathrm{C}$ and hydroxycinnamic acid derivatives (Al-Remi et al., 2018). Turkey ranks fourth in the world with 12.6 million tons of tomato production (FAO, 2019). Especially in recent years, there has been a significant increase in yield due to the use of grafted seedlings in tomato cultivation. According to the 2019 data, the tomato is the first among the most produced vegetables $(26,7 \%)$ in, Turkey (TUIK, 2019). Due to the effect of climate 
factors and intensive greenhouse activities, the highest tomato production is made in Antalya with 2.4 million tons (TUIK, 2019).

There are many pests that cause problems in tomato production areas. Among these, plant parasitic nematodes are in the first place due to the level of economic damage they cause (Karssen and Moens, 2006; Sasser, 1986). Root-knot nematodes is one of serious pests groups of vegetable production in world and Turkey (Gürkan et al., 2019). It is known that annual crop losses caused by root-knot nematodes can reach up to $80 \%$ in vegetables (Sasser, 1986). Some researches reported that the crop loss caused by root-knot nematodes in tomatoes is to be 42-54\% (Netscher and Sikora, 1990).

Meloidogyne incognita (Kofoid \& White, 1919) Chitwood and Meloidogyne javanica (Treub, 1885) Chitwood were dominant species in coastal regions of Turkey (Uysal et al., 2017). The nematodes are recorded in the roots of sugar beet plant in Samsun for the first time by Iyriboz in 1934 in Turkey. It is known that these nematodes also cause significantly economic loses in Turkey. Söğüt \& Elekcioğlu (2007) found that yield losses of about $80 \%$ in pepper greenhouses in Adana. In another recently studies, M. incognita were reported in Kahramanmaraş Province in the Eastern Mediterranean Region (Çetintaş and Çakmak, 2016).

The negative effects of nematicides used for the control of root-knot nematodes are known in many studies (Gowen, 1997; Waldo et al.2019). On the other hand, the chemical application methods are quite difficult and expensive. In addition to the high costs, the application of nematicides often causes harmful environmental side effects that reduce the success of integrated nematode management. So, the using of non-chemical management strategies is recommended to avoid such disadvantages (Gowen, 1997).Therefore, research on the development of alternative methods against pesticides has increased in recent years. The use of resistant varieties and grafted seedlings are alternative methods that have been used extensively to control nematodes (Lopez-Perez et al., 2006; Sen et.al., 2018). These methods provide a lower cost, more effective and longer-lasting protection, especially compared to chemical applications. It is also preferred because of its environmental friendliness (Lopez-Perez et al., 2006).

This study was carried out in order to determine the presence, species and density of root-knot nematodes in tomato greenhouses in which non-grafted or grafted tomato seedlings are grown in Antalya Province and some districts where tomato cultivation is intensely carried out under cover.

\section{Material and Method}

Root and soil samples taken from tomato plants showing signs of infection with root-knot nematodes in greenhouses in Antalya Province constituted the main materials of the study. Accordingly, soil and root samples were taken using the guided sampling method in numbers to represent the greenhouse during the removal of the plants after harvesting in areas where greenhouse cultivation is intense. The samples brought to the laboratory of Uşak University, Scientific Analysis and Technological Application and Research Center (UBATAM) were preserved at 4 degrees. The samples were washed by pre-soaking not to damage the roots, and after washing, each was laid on blotter paper and allowed to dry in room conditions. The severity of gall formation on the roots after drying was evaluated using the root-knot scale developed by Zeck (1971). "Blender-Sieve-Centrifuge method" developed by Coolen and D'Herde (1972) was used to obtain females from galled roots. Egg cluster count in the roots was made using food coloring. The permanent preparations of females individuals were prepared using the "Perineal Samples Preparation Method" developed by Hartman and Sasser (1985) given by Taylor and Netscher (1974). For the isolation of nematodes, $100 \mathrm{gr}$ soil taken from $1 \mathrm{~kg}$ soil sample brought from the greenhouse was made into solution. The second stage larvae of the nematodes were counted under an advanced light microscope at 40X magnification. Prof. Dr. Ramazan ÇETINTAŞ (Kahramanmaraş Sütçü İmam University) made morphological diagnosis of nematodes considering the perineal patterns of adult female nematodes.

\section{Results and Discussion}

The species and population densities of root-knot nematodes in the roots of non-grafted or grafted tomato plants in greenhouses located in regions where tomato cultivation is intensively made in Antalya Province were investigated. During field studies, signs of nutrient deficiency, growth retardation, weakness, wilting, drying, misshapened fruit, shrinkage, gall formation in the roots (Figure 1) and yield and quality loss were observed in plants infected with root-knot nematodes. 

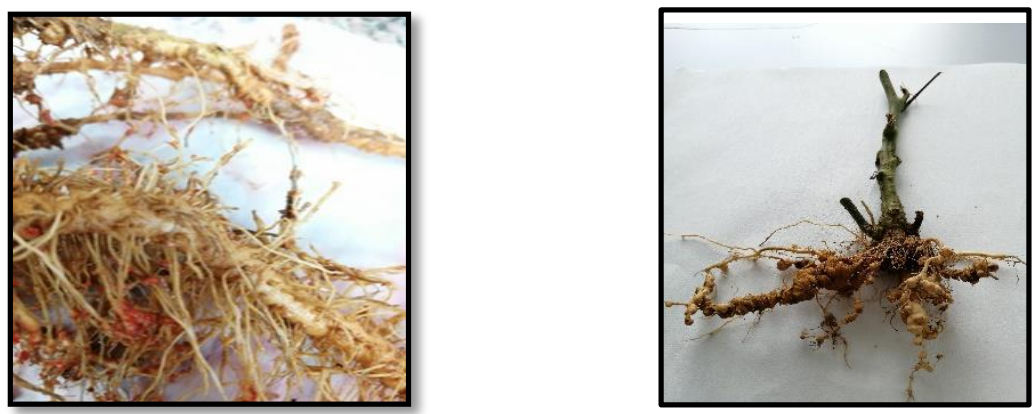

Figure 1. An infected root sample stained with red food coloring (left) and unstained infected root sample (right)

In laboratory studies, perineal preparations made using female root-knot nematodes detected in tomato roots were photographed under advanced microscope. (Figure 2). Morphological diagnosis of nematodes was made as a result of the examination of the photographs of permanent perineal preparations. Accordingly, only M. incognita species were found in the roots of grafted tomato plants in both years. In the roots of non-grafted tomato plants, both $M$. incognita and M. javanica species were detected.
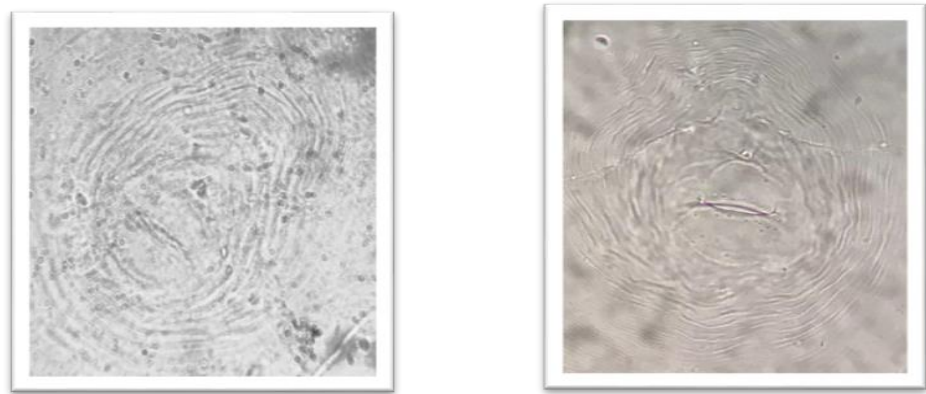

Figure 2. Photos of the perineal preparations of Meloidogyne incogniata (left) and Meloidogyne javanica (right) obtained from female root-knot nematodes

The species identified as a result of our study are those that are frequently found in the Mediterranean region. It is reported that $M$. incognita and $M$. javanica is the most common and economical species in Turkey in the study by Elekcioğlu and Uygun (1994). Addition, in the study by Şeker (2012), $M$. incognita and M. javanica were determined with the previously in the areas grown fruit and vegetable in Turkey.

In this study, it was determined that 10 of the 58 samples taken from grafted tomato plants in 2019 and 8 of the 48 samples taken in 2020 were infected with nematodes in this study. In non-grafted tomato plants, it was determined that 42 of 67 samples taken in 2019 and 40 of 62 samples taken in 2020 were infected with nematodes. According to this data, the percentages of nematode infections in total grafted and non-grafted tomato plants were determined in 2019-2020 (Table 1). 
Table 1. The percentages of infections with nematodes in total grafted and non-grafted tomato plants in

\begin{tabular}{|c|c|c|c|c|c|c|}
\hline Districts & $\begin{array}{c}\text { Infection } \\
\text { rate in } \\
\text { grafted } \\
\text { tomatoes in } \\
2019(\%)\end{array}$ & $\begin{array}{c}\text { Infection } \\
\text { rate in } \\
\text { grafted } \\
\text { tomatoes in } \\
2020(\%)\end{array}$ & $\begin{array}{c}\text { Infection rate } \\
\text { in total } \\
\text { grafted } \\
\text { tomatoes in } \\
2019-2020 \\
(\%)\end{array}$ & $\begin{array}{c}\text { Infection rate } \\
\text { in non- } \\
\text { grafted } \\
\text { tomatoes in } \\
2019(\%)\end{array}$ & $\begin{array}{c}\text { Infection rate } \\
\text { in non-grafted } \\
\text { tomatoes in } \\
2020(\%)\end{array}$ & $\begin{array}{c}\text { Infection } \\
\text { rate in total } \\
\text { non grafted } \\
\text { tomatoes in } \\
2019-2020 \\
(\%)\end{array}$ \\
\hline Serik & 37,50 & 28,57 & 33,33 & 75,00 & 80,00 & 77,50 \\
\hline Manavgat & -- & -- & -- & 71,42 & 64,28 & 67,85 \\
\hline Aksu & 33,33 & 33,33 & 33,33 & 80,00 & 75,00 & 77,77 \\
\hline Kepez & -- & -- & -- & 20,00 & 37,50 & 27,77 \\
\hline Muratpaşa & -- & -- & -- & 37,50 & 37,50 & 37,50 \\
\hline TOTAL & 17,24 & 16,66 & 16,98 & 62,68 & 64,51 & 63,56 \\
\hline
\end{tabular}

Accordingly, it was found that $16,98 \%$ of the total samples taken from grafted tomato plants in 20192020 were infected with nematodes. However, in non-grafted tomato plant, 63,56\% of the total samples taken in two years were found to be infected with nematodes. The percentage of infection with nematodes in grafted samples was very lower than non-grafted ones. In some researches about grafted plants, researchers reported that grafting vegetables on resistant rootstocks is a mean of controlling root-knot nematodes in areas with intensive land use like greenhouse (Lee, 1994; Lopez-Perez et al., 2006).

Infection rates in some previously studies made about the root-knot nematode in different regions and plants were researched in Turkey. Ayhan and Kaşkavalc1 (2015) conducted a study on the identification and prevalence of root-knot nematodes (Meloidogyne spp.) in areas grown pickled cucumber (Cucumis sativus L.) in Ödemiş and Kiraz districts. They found that the prevalence in Ödemiş was $17,74 \%$ and it was $17,65 \%$ in Kiraz. Enneli (1980) reported that the root-knot nematode infestation rate in Central Anatolia is $10-94 \%$.

According to study, while the mean root-knot scale value of grafted tomato plants found to be infected with nematodes was $2,05 \pm 0,99$, the mean root-knot scale value in non-grafted plants was found to be 4,18 $\pm 1,61$ (Figure 3). In another study on the root-knot scala, Akyazi and Ecevit (2011) identified only $M$. incognita species, one of the root-knot nematodes in vegetable fields in Tokat. They reported that although the Zeck scale was high in some non-grafted plants infected with $M$. javanica, egg formation was low. The reason why this nematode species was not detected in grafted plants in our study may be due to the lack of reproductive capacity or lower reproductive capacity in grafted tomato plants depending on the plant variety.

As a result of the counts of the second stage juveniles in the soil samples, the mean of population density per 100 gram soil taken from grafted tomato plants in 2019 - 2020 was 132,22 $\pm 55,78$ nematodes, while the mean of population density in soil taken from non-grafted tomato plants was $1272,92 \pm 1683,27$ nematodes (Figure 4). In addition, when the data about population densities in soils belonging to infected non-grafted tomato plants in 2019 - 2020 were examined according to nematode species, while the mean of population density of $M$. incognita was recorded as 1252,13 $\pm 1910,56$ nematodes, the mean of population density of $M$. javanica was as 1333,33 $\pm 720,64$ nematodes. 


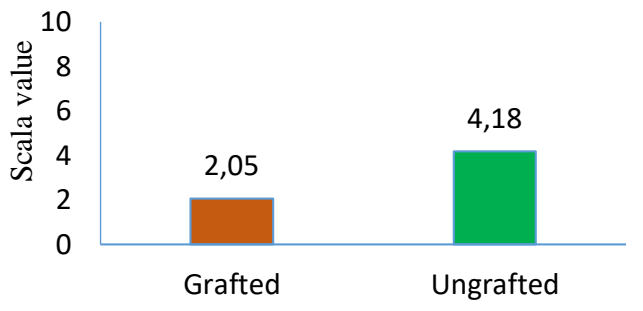

Figure 3. The means of Zeck rootknot scale values in grafted and nongrafted tomato plants infected with nematodes in 2019-2020

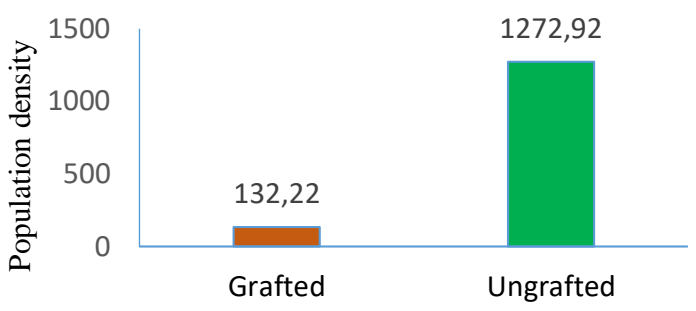

Figure 4. The means of population densities in soils from grafted and nongrafted tomato plants infected with nematodes in 2019-2020 (second-stage juveniles (J2) per 100 gram soil)

In conclusion, in this study conducted between 2019 - 2020 in Antalya Province, it was determined that the rate of infection with nematodes, average population density and the severity of gall formation on the roots in grafted tomatoes were lower than the non-grafted ones. The low population density of nematodes in plants grown by using grafted seedlings shows that the use of grafted seedlings is a good alternative to the chemical method in controlling these soil-borne nematodes. Continuing studies on the spread and population density of root-knot nematodes in the Provinces like Antalya where one of the most important sources of income is greenhouse cultivation, training farmers about control of plant nematodes and taking the necessary measures are important for the future of agriculture.

\section{Acknowledgments}

The authors thank to Prof. Dr. Ramazan ÇETINTAŞ from Kahramanmaraş Sütçü İmam University for morphological diagnosis of nematodes species. In addition, Betül GÜRKAN is thanked for her assistance in laboratory work from Eastern Mediterranean Passage Zone Agricultural Research Institute, Plant Protection Department.

\section{References}

Akyaz1, F. and Ecevit, O. (2011). Distribution and species identification of root knot nematodes (Meloidogyne spp.) In the vegetable areas of Tokat Province. Anadolu Journal of Agriculture Science, 26(1):1-9. Tokat.

Al-Remi, F., Arvas, Y. E., Durmuş, M., Kaya, Y. (2018). Tomato Plant and Its In Vitro Micropropagation. Journal of Engineering Technology and Applied Sciences, 3(1): 57-73.

Ayhan, E. C. and Kaşkavalcı, G. (2015). Identification and Prevalence of Root-Ur Nematodes (Meloidogyne spp.) In Pickled Cucumber (Cucumis sativus L.) Areas in Ödemiş and Kiraz (İzmir) Districts. Ege University Faculty of Agriculture Journal. 52(2): 227-234.

Cavaness, F. R. and Jensen, H. J. (1955). Modification of the Centrifugal-flotation technique for isolation and concentration of nematodes and their eggs from soil and plant tissue. Proceedings of the Helminthological Society of Washington, 22: 87-89.

Coolen, W.A. and D’Herde, C.J. (1972). A Method for the Quantitative Extraction of Nematodes from Plant Tissue. Publication of the State Nematology and Entomology Research Station, Merelbeke, Belgium, 77 p.

Çetintaş, R. and Çakmak, B. (2016). Meloidogyne species infesting tomatoes, cucumbers and eggplants grown in Kahramanmaraş Province, Turkey. Turkish Journal of Entomology, 40 (4): 355-364. 
Elekçioğlu, İ. H. and Uygun, N. (1994). "Occurrence and distribution of plant parasitic nematodes in cash crops in eastern Mediterranean region of Turkey, 409-410”. Procedings of 9 th Congress of the Mediterranean Phytopathological Union (18-24 September 1994, Kuşadası-AydınTurkey), $567 \mathrm{p}$.

Enneli, S. (1980). The Definition, Biology, Histopathology and Pathogenicity of Root Knot Nematode (Meloidogyne incognita Chitwood) Harmful in Tomatoes Grown in Central Anatolia Region. A.Ü.Institute of Science Doctoral Thesis (Unpublished), Ankara,129 p.

FAO. (2019). World Fresh Fruit and Vegetable Area, Yield and Amount, Access date 10.0.2019. Access address, http://www.fao.org/faostat/en/\#data/QC.

Gowen, S.R. (1997). Chemical control of nematodes: efficiency and side-effects. FAO Plant Production and Protection Paper, vol. 144, pp. 59-65.

Gürkan, B. Çetintaş, R., Gürkan, T. (2019). Identification of Root-knot Nematode Species (Meloidogyne spp.) Found in Gaziantep and Osmaniye Vegetable Fields and Determination of Some Nematode Population Breeds. Kahramanmaraş Sütçü İmam University, Journal of Agriculture and Nature, 22 (extra 1): 113-124.

Hartman, K. M. and J. Sasser, N. (1985). "Identification of Meloidogyne species on the Basis of Differential Host Test and Perineal-Pattern Morphology, 69-77". In: An Advanced Treatise on Meloidogyne Volume II:Methodology (Eds. K. R. Barker, C. C. Carter \& J.N. Sasser).North Carolina State University Graphics, Raleigh, North Carolina, USA, 223 pp.

İyriboz, N. (1934). Sugar beet Diseases. Illustrated Moon Printing House, T.L.Ş., İstanbul.

Karssen, G. and Moens, M., (2006). Root-knot nematodes. In: Perry, R.N. and Moens, M. (Eds). Plant nematology. Wallingford, UK, CABI Publishing, pp. 59-90.

Lee, M. (1994). Cultivation of grafted vegetables. I. Current status, grafting methods and benefits. HortScience 29: 235-239.

Lopez-Perez, J. A., M. L. Strange, I. Kaloshian and Ploeg, A.T. (2006). Differential responce of Mi gene resistant tomato rootstocks to root-knot nematodes (Meloidogyne incognita). Crop Protection, 25: 382-388.

Netscher, C. and Sikora, R.A. (1990). Nematode parasites on vegetables. M., Luc, R.A., Sikora, J., Bridge. Plant Parasitic Nematodes in Subtropical and Tropical Agriculture. CAB International, 231-283.

Sasser, J. N. (1986). Economic importance of Meloidogyne in tropical countries In: Root-knot nematodes (Meloidogyne species) systematics, biology and control. Ed: Lamberti, F. and C.E. Taylor, Newyork Academic Press. 256-268. London.

Sen, A., Chatterjee, R., Bhaisare, P. and Subba, S. (2018). Grafting as an Alternate Tool for Biotic and Abiotic Tolerance with Improved Growth and Production of Solanaceous Vegetables: Challenges and Scopes in India. International Journal of Current Microbiology and Applied Sciences. Volume 7 Number 01:121-135.

Söğüt, M. A. and Elekçioğlu, İ.H. (2007). Methyl Bromide alternatives for controlling Meloidogyne incognita in pepper cultivars in the Eastern Mediterranean region of Turkey. Turkish Journal of Agriculture and Forestry, 32 (1): 31-40.

Taylor, D. P. and Netscher, C. (1974). An improved technique for preparing perineal patterns of Meloidogyne spp. Nematologica, 20:268-269. 
TÜIKK. (2019). Turkey Total Fresh Fruit and Vegetable Production Data (tons), Access Date 12.04.2019. Access address, https://biruni.tuik.gov.tr/medas $/ \mathrm{kn}=92 \&$ locale=tr.

Uysal, G., Söğüt M.A. and Elekcioğlu İ.H. (2017). Identification and distribution of root-knot nematode species (Meloidogyne spp.) in vegetable growing areas of Lakes Region in Turkey. Turkish Journal of Entomology, 2017, 41 (1): 105-122.

Waldo, B. D., Grabau, Z. J., Mengistu, T. M. and Crow, W.T. (2019). Nematicide effects on nontarget nematodes in bermudagrass. Journal of Nematology,| Vol. 51, 1-12.

Zeck, W.M. (1971). A rating scheme for field evaluation of Root-knot nematode infestation. Pflanzenschutz Nachrichten, Bayer. Published by Farbenfabriken Ag. Leverkusen, 10:141-144. 